\title{
desestranhamento em relação ao alemão na aprendizagem do idioma: um processo de aproximação ao "outro" sob a perspectiva da competência intercultural
}

The destrangement in relation to the German language in the foreign language learning process: approximation to the "other" under the perspective of the Intercultural

\author{
Competence
}

\author{
Cibele Cecilio de Faria Rozenfeld ${ }^{1}$ \\ Nelson Viana ${ }^{2}$
}

\begin{abstract}
This article aims to approach, under a critical perspective, images about German language and their speakers, presented by Brazilian university students interested in or engaged in learning this language in the first stage of studies. The purpose is to deal with evidences of the occurrence of stereotypical images and to discuss their implications in/for the teachinglearning process, aiming with this study to show the importance of considering and establishing as a relevant goal in the teaching of German, the necessity of a "destrangement" route or period, through a methodological approach aimed at helping the students in the process of developing intercultural competence. Such discussions are founded in theoretical conceptions related to the notions of "other" and "self", intercultural competence, intercultural approach, as well as in results obtained through an investigation conducted within the field of foreign language (German) learning.
\end{abstract}

Keywords: images about German language, destrangement, intercultural competence.

\footnotetext{
${ }^{1}$ Doutora pelo programa de Linguística e Língua Portuguesa da Faculdade de Ciências e Letras da Universidade Estadual de São Paulo, UNESP, campus Araraquara e Mestre na área de Linguística: Ensino de Línguas, pela Universidade Federal de São Carlos. (ciberoz@yahoo.com.br)

2 Professor do Departamento de Letras e do Programa de Pós-Graduação em Linguística (linha de pesquisa: ensino de línguas) da Universidade Federal de São Carlos. Doutor em Linguística Aplicada: Ensino de Língua Estrangeira (UFMG) e Mestre em Linguística Aplicada: Ensino/Aprendizagem de Segunda Língua e Língua Estrangeira (Unicamp). (nlsviana@ufscar.br)
} 
Rozenfeld, C.Niana, N. - O desestranhamento

Resumo: Sob uma perspectiva crítica, são abordadas neste artigo, imagens sobre a língua alemã e seus falantes, apresentadas por estudantes universitários brasileiros, interessados em aprender esse idioma ou engajados em estágio inicial de sua aprendizagem. O propósito é discutir evidências de imagens estereotipadas, bem como refletir sobre possíveis decorrências dessas imagens no/para o processo de ensino-aprendizagem da língua, buscando, com isso, apontar a importância de se considerar como objetivo relevante no ensino de alemão, a necessidade de um percurso de "desestranhamento" do idioma, por meio de enfoque metodológico orientado para auxiliar os aprendizes no processo de desenvolvimento de competência intercultural. Tais reflexões têm como base pressupostos teóricos como as noções de outro e de próprio, as concepções de competência intercultural e de ensino intercultural, e resultados obtidos em pesquisa desenvolvida no campo de ensino e aprendizagem de língua estrangeira (alemão).

Palavras-Chave: imagens sobre a língua alemã, desestranhamento, competência intercultural.

\section{Introdução}

Podemos observar na sociedade contemporânea, caracterizada fortemente por tecnologias que possibilitam a redução de distâncias, o rompimento de barreiras de tempo e a intensificação de contatos entre membros de diferentes culturas, um número cada vez maior de pessoas que buscam o conhecimento de língua(s) estrangeira(s). Nota-se que tal fato é impulsionado, entre outras razões, por demanda do mercado de trabalho atual, que exige profissionais capazes de circular sem dificuldades entre fronteiras, bem como por necessidade de entender o outro em sua complexidade.

O ponto de partida da discussão que apresentamos neste trabalho é o fato de que imagens iniciais da língua e cultura estrangeira podem exercer forte influência no processo de ensino e aprendizagem. Como postula AlmeIDA FILHO, a "língua estrangeira pode significar língua dos outros", "de estranhos, de bárbaros, de dominadores, ou língua exótica" para os alunos (2008:11), fato sobre o qual o professor deve refletir.

Dentre as pessoas que buscam a aprendizagem de uma Língua Estrangeira (LE) é comum encontrarmos aquelas que possuem imagens negativas relativas à língua alemã, originadas por sua sonoridade, frequentemente referida como "estranha" ou "ríspida"; por sua grafia, apontada como "impossível"; ou relativas ao povo, considerado em geral "sério", "frio" (cf. RozEnFELD, 2007). Como resultado dessas caracterizações, muitas dessas pessoas optam pelo estudo de uma língua "mais fácil", "menos estranha"; outras, entretanto, e em função de considerarem a importância da 


\section{Rozenfeld, C.Niana, N. - O desestranhamento}

língua alemã em relação a aspectos econômicos, culturais e educacionais, mantêm a decisão de aprender o idioma e, certamente, adentram/adentrarão a sala de aula imbuídas de tais imagens, fato que poderá converter-se em aspecto nocivo à aprendizagem.

Em consonância com essas considerações, iniciaremos este trabalho tecendo algumas reflexões sobre a noção de outro, em relação dicotômica à de próprio. Em seguida, abordaremos o conceito de competência intercultural (CI) de acordo com estudiosos da área e relataremos percurso e resultados de pesquisa enfocando imagens sobre a língua alemã e sobre o povo a ela relacionado, apresentadas por estudantes universitários na condição de interessados em aprender alemão ou na condição de aprendizes desse idioma. Finalizaremos propondo um enfoque orientado pelo/para o desenvolvimento da CI como caminho favorável ao processo de desestranhamento do outro, à aproximação da cultura-alvo e à aprendizagem da língua.

Postulamos, com este/neste trabalho, que imagens estereotipadas quanto à língua e ao povo alemão são passíveis de mudanças, partindo de uma percepção de estranhamento e movimentando-se para uma percepção de (relativa) familiaridade (com níveis moventes de ajustes) em relação a suas peculiaridades, ou seja, constituindo um processo de desestranhamento "do outro", como parte do desenvolvimento da competência intercultural.

\section{2. $\bigcirc$ próprio e o estranho em LE: uma relação dicotômica}

Levando em consideração o que foi exposto, defendemos que uma maneira de atuar favoravelmente no processo de aprendizagem de LE seja rumar em direção à melhor compreensão do outro, que também permite melhor compreensão de si. Para tanto, fazse necessário, inicialmente, discorrermos sobre os sentidos de outro.

De forma geral, pode-se afirmar que o outro é aquele que se opõe ao próprio. Existem inúmeras marcas apresentadas pelo outro como, por exemplo, outra estatura, cor de olhos, forma de vestir, outro nariz, tipo de cabelo, gênero. Para reconhecermos as características da alteridade faz-se necessário percebermos a distinção entre as 
características de caráter corporal-natural e as de caráter sócio-cultural (Cf. WEINRICH, 1998).

No entanto, as características naturais corporais, bem como as de caráter sóciocultural, não necessariamente registram (ou provocam) estranhamento, pois aspectos como o vestuário de uma pessoa, moradia ou sua aparência podem ser percebidos como sinais interessantes que marcam um indivíduo ou um grupo. Dessa forma, podemos concluir que o outro, não necessariamente, causa estranhamento; não é a alteridade que marca o estranho.

Quando pessoas desejam falar umas com as outras, mas não são capazes, por falarem línguas diferentes, a língua do outro pode se apresentar, num primeiro momento, como estranha. Todavia, a língua estrangeira não tem necessariamente a característica do estranho. Na verdade, sabe-se que duas pessoas são capazes de se comunicar, mesmo uma não tendo conhecimento da língua da outra, por meio de gestos, de outra língua estrangeira, do olhar, ou mesmo de um tradutor. A língua estrangeira pode soar familiar e assim, por vezes, apesar de não se ter o conhecimento dela, é possível inferirmos sentidos, alguns significados de textos ou discursos. Nessa situação, a LE é outra, mas não estranha.

Entretanto, nem sempre isso ocorre e, dependendo de variáveis que caracterizam determinada língua ou determinado povo, o resultado ao estrangeiro pode ser a percepção de algo estranho.

A questão central, nesse caso, torna-se, portanto, o estranhamento (Fremdheit). O estranho é definido pelo tipo de interpretação que se faz do outro como tal; o que torna o outro instigante é ele como estranho, em relação dialética ao próprio. (Cf. WEINRICH 1998).

O autor BAUSINGER (1998) afirma que o estranho não é objetivo. Ele não parece estar em coisas concretas como em paisagens, em objetos; trata-se, na verdade, de uma atribuição que nasce no plano subjetivo. Quando afirmamos que algo é estranho, isso significa que é estranho para mim, para o próprio. Por essa razão, o estranho não é sempre estranho, visto que ele pode se relativizar, suavizar ou se deslocar.

Muitas pessoas privilegiam o próprio e desvalorizam o que é estranho. Esse fenômeno já é bastante conhecido há muitos anos no campo da sociologia como etnocentrismo. Porém, mais recentemente, os estudos como de WIERLACHER et. al. 


\section{Rozenfeld, C.Niana, N. - O desestranhamento}

(1998) evidenciaram que o outro não é necessariamente o estranho. Interpretamos a alteridade segundo princípios individuais, segundo lembranças culturais, medos, esperança e damos, assim, um sentido de estranhamento específico (op.cit., 1998).

De acordo com DoRnBuSCH, Todorov reconhece quatro fases na alteridade e compreensão do outro (1998:16-17):

1. Num primeiro momento, assimila-se o outro a si próprio, existindo apenas uma identidade: eu mesmo. Se, por exemplo, estou interessado em culturas distantes das minhas, organizo-as de acordo com a minha própria. Nessa etapa, o meu conhecimento do outro é apenas quantitativo e não qualitativo.

2. Num segundo passo, elimina-se a própria identidade em benefício do outro. Eliminando a minha subjetividade, acredito estar sendo objetivo. Aqui, novamente, também temos uma única identidade: nesse caso, a do outro. Nesta etapa busco, por exemplo, o máximo de informações sobre a Alemanha. [...], tentando ver o mundo através de seus olhos.

3. Nesta fase eu reassumo minha própria identidade [...]. Concluo que meus valores são tão relativos quanto os do outro. A dualidade, aqui, substitui a unidade, sendo que o eu estabelece-se como diferente do outro.

4. Na última fase do conhecimento [...] eu não quero nem sou mais capaz de me identificar com o outro, nem posso mais identificar-me comigo mesmo. Em outros termos: o conhecimento do outro depende de minha própria identidade. [...] interagindo com o outro, portanto, meus conceitos transformaram-se de uma tal maneira que responde por ambos - por mim e pelo outro.

A autora verificou ainda que Todorov distingue, em trabalho anterior (A conquista da América), três planos de alteridade: "o axiológico, o praxiológico e o epistêmico" (DORNBUSCH 1998: 17). No primeiro plano, axiológico, faz-se um julgamento de valor acerca do outro, no sentido de: ele é "bom", ou "mau”, eu "gosto", ou "não gosto" dele, ele é "inferior", ou "igual” a mim, correspondendo à primeira fase de sua divisão anterior. No eixo praxiológico observa-se uma aproximação ou distanciamento do outro, adotando os valores do outro ou priorizando a própria identidade. Este eixo é identificado à segunda e terceira fase da alteridade citadas anteriormente. No eixo epistêmico nota-se "ou o conhecimento ou a desconsideração da identidade do outro", correspondendo, portanto, à quarta fase da alteridade (DORNBUSCH 1998: 17-18). 
HogREBE (1998), por sua vez, distingue três negações centrais, para se afirmar que algo é estranho (fremd $)^{3}$ a alguém: a negação do pertencimento, a negação de um conhecimento e a de uma confiabilidade ${ }^{4}$. O primeiro caso refere-se à negação do pertencimento de coisas ou pessoas a grupos, classes, porções objetivas. No segundo, não se trata de questões objetivas, mas de negação de um conhecimento que o próprio falante não possui. No terceiro caso, a referência pode se dar em três níveis: algo se tornou estranho para mim, algo é ainda estranho, ou algo não me é mais estranho.

No caso de língua estrangeira, o estranhamento, em alguns casos, pode significar desafio ao aluno, e por essa razão, pode ter como efeito positivo a motivação para a aprendizagem. No entanto, ele pode, por outro lado, levar a um bloqueio ou distanciamento do objeto de estudo.

WEINRICH (1998) afirma que “o estranhamento da língua estrangeira é o maior inimigo da didática de LE e, por isso, deve-se desvendá-lo muito bem para ser possível combatê-lo de forma eficaz". 5 O autor focaliza aquele estranhamento que leva ao distanciamento, ao afastamento em relação ao outro, bem como a falsos julgamentos sobre a alteridade.

Nesse sentido, compreendemos o desestranhamento ${ }^{6}$ do estranho como objetivo central do ensino intercultural: a desconstrução da interpretação que distancia a compreensão do outro.

Na perspectiva do ensino intercultural busca-se alcançar (maior) sensibilização e tolerância diante das diferenças, não apenas no campo linguístico, mas também frente a aspectos da cultura-alvo e a características de seus membros. Além disso, busca-se a

\footnotetext{
${ }^{3}$,So liegen der Behauptung, dass etwas jemandem fremd sei, eigentlich drei Verneinungen zugrunde: die Verneinung einer Zugehörigkeit, die Verneinung eines Wissens, die Verneinung einer Vertrautheit [...] “ HOGREBE (1998:104)

${ }^{4}$ As traduções das referências em língua estrangeira (alemão ou inglês) deste trabalho foram realizadas por nós.

5 „Die Fremdheit der Fremdsprachen ist die große Feindin der Fremdsprachendidaktik und man muss sie gut ausprähen, um sie wirkungsvoll bekämpfen zu können“ (WEINRICH, 1998:19).

6 Em relação ao próprio termo, torna-se relevante considerar que, em português, o vocábulo desestranhamento nos auxilia semanticamente a compreender o processo que se apresenta como central neste trabalho. Da mesma forma, em língua inglesa, o termo destrangement, embora não seja utilizado, conforme pudemos verificar, em contextos de ensino-aprendizagem de línguas, apresenta-se também adequado, uma vez que indica o sentido de tornar familiar algo estranho. Em alemão (idioma-foco do estudo), não encontramos um termo que expressasse, sob uma perspectiva de paralelismo semântico, o sentido de desestranhamento, sendo Annäherung o que pudemos perceber como mais próximo. Por essa razão, propomos sua expressão, nesse idioma, por meio do termo Rückentfremdung, com o propósito de buscar construir o sentido reverso de Entfremdung.
}

Pandaemonium, São Paulo, n. 17, Julho/2011, p. 259-288 - www.fflch.usp.br/dlm/alemao/pandaemoniumgermanicum 
reflexão acerca da própria identidade e dos próprios valores, que são tomados por vezes como verdades absolutas ou naturais e não como produto da influência sócio-cultural.

Nos estudos da compreensão do outro, destacamos Alois WIERLACHER (1994, 1998 e KRUSCHE et al. 1990). O autor foi um dos responsáveis pela constituição da Interkulturelle Germanistik como parte da ciência da cultura que ocorreu nos anos $80 \mathrm{e}$ também um dos fundadores, da Gesellschaft für Interkulturelle Germanistik (GIG), em 1984, na Alemanha. A GIG é uma associação que se dedica à realização de eventos, à promoção de intercâmbios na área e ao desenvolvimento de estudos que estabeleçam uma relação entre a própria cultura e a cultura alheia em relação dialética (Cf. WIERLACHER et al., 1998).

Diante das premissas apresentadas, defendemos como relevante no ensino de alemão estabelecer, entre outros objetivos, o de favorecer ao aprendiz o desenvolvimento da capacidade de conhecer melhor a própria identidade e os seus valores e o de promover melhor compreensão do diferente, do outro em relação ao próprio.

No próximo item discutiremos o conceito de competência intercultural como habilidade que possibilita alcançar tais objetivos, bem como sua interface com a proposta de ensino intercultural, para, em seguida, discutir a importância desses conceitos no ensino e aprendizagem de alemão.

\section{A competência e o ensino intercultural: breve discussão de conceitos e estudos}

Existe um consenso entre estudiosos contemporâneos da área de ensino de LE quanto à indissolubilidade das noções de língua e de cultura, principalmente tomando-se a vertente antropológica e simbólica de cultura. Todavia, ainda há poucas pesquisas que focalizem a relação língua/cultura na comunicação/interação (Cf. VIANA, 2003: 86).

A partir da década de 70, observamos no campo da Línguística Aplicada uma maior preocupação com o papel da cultura na e com as diferenças culturais para a comunicação em LE. Autores como Hymes (1972), CAnale E SWAin (1980), 
WidDOWson (1978), Kramsch (1993) e, no Brasil, AlmEIDA FilHo (2008), são alguns exemplos de estudiosos que contribuíram fortemente para o paradigma comunicativo vigente até a atualidade, o qual evidencia a relevância de aspectos culturais da línguaalvo no ensino de LE.

O conceito de Competência Intercultural (CI) surge a partir dos pilares da relação entre língua e cultura na interação, bem como das concepções de interculturalidade, comunicação intercultural, Interkulturelle Germanistik, todos com base teórica (e aplicação) também nos campos da antropologia, da sociologia, da psicologia e da comunicação. Tais conceitos adquirem expressividade no contexto contemporâneo, marcado pela globalização, pela rápida troca de informações e intercâmbio cultural e evidenciam desafios das/nas interações culturais.

VOLKMANN et al. (2002) se referem ao conceito de Competência Intercultural como a "nova palavra mágica" (neues Zauberwort), pois, por seu intermédio, busca-se uma comunicação entre culturas mais pacífica e harmônica ${ }^{7}$. Segundo os autores, a CI é definida como:

[...] a capacidade e habilidade de aprendizes de LE, e de forma geral, de atores envolvidos em um encontro intercultural, de conhecer as diferenças entre a cultura-alvo e a própria, de reconhecer essas diferenças em situações concretas e de desenvolver estratégias para lidar de forma compreensiva com os costumes da outra cultura ${ }^{8}$. (VOLKMANN et al., 2002:7)

Conforme VOLLMUTH (2002) “se CI não significa o simples conhecimento, mas também reflexão sobre o outro, é necessário que se teçam comparações com a própria cultura"9 (2002: 49). Para a autora, isso é imprescindível, para que se evite a formação de estereótipos e para que se possa transmitir uma impressão realística e multifacetada da cultura-alvo. Nesse sentido, VOLKMANN et al. (2002:7) compreendem o desenvolvimento de CI como um objetivo que vai além da aquisição dos conhecimentos

${ }^{7}$ „Als neues Zauberwort hat...der Begriff interkulturellen Kompetenz Konjunktur..Mit ihrer Vermittlung wird eine reibungslosere interkulturelle Kommunikation angestrebt $[\ldots]^{\text {“ }}$

${ }^{8}$ „Der Begriff IK lässt sich allgemein als Fähigkeit und Fertigkeit von Fremdsprachenlernern, ja überhaupt von Akteuren einer interkulturellen Begegnung begreifen, über Differenzen zwischen der eigenen und der Zielkultur zu wissen, diese in konkreten Situationen zu erkennen und Strategien zu entwickeln, einfühlsam auf die Gepflogenheit der anderen Kultur einzugehen.“

9 „Wenn IK nicht blo $\beta$ Kennenlernen, sondern auch Reflexion des Fremden bedeutet, muss man Vergleiche mit der eigenen Kultur zulassen." 
puramente factíveis sobre a geografia, costumes e produção linguística, englobando também o conhecimento sobre modelos de comunicação e comportamento de pessoas de outras culturas.

STIERSTOFER (2002: 119) enfatiza a dimensão dinâmica da CI que visa, por meio de desdobramento processual, transpor o vazio entre a LM e a LE e entre a própria cultura e a cultura-alvo. $\mathrm{O}$ autor representa tal processo da forma que apresentamos na Figura $1^{10}$.

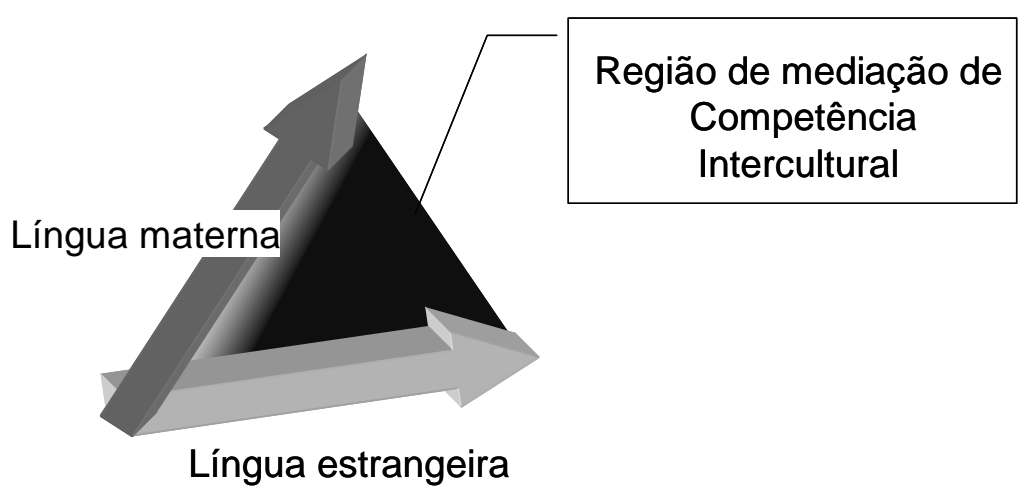

Figura 1: Representação da região de mediação da CI

WEIER (2002: 166) aponta para a dificuldade de definição do termo e atribui tal dificuldade às diferentes implicações relacionadas a ele. A autora caracteriza CI como a competência baseada em capacidades humanas gerais como a de empatia, de tolerância frente a ambiguidades e de manejo de conflitos e postula que a CI deve servir a situações em que estão envolvidas a compreensão entre os povos e a política de paz. ${ }^{11}$ Ela propõe diferentes elementos envolvidos na CI, os quais se encontram representados na Figura $2^{12}$.

\footnotetext{
10 Representação baseada no modelo de STIERSTOFER (2002:119)

${ }^{11}$ Interkulturelle Kompetenz, soll (...) der Völkerverständigung und Friedenspolitik dienen und basiert auf allgemeinmenschlichen Fähigkeiten wie Empathiefähigkeit, Ambiguitätstoleranz, Konfliktfähigkeit, etc.

${ }^{12}$ Representação baseada no modelo de WEIER (2002:168)

Pandaemonium, São Paulo, n. 17, Julho/2011, p. 259-288 - www.fflch.usp.br/dlm/alemao/pandaemoniumgermanicum
} 


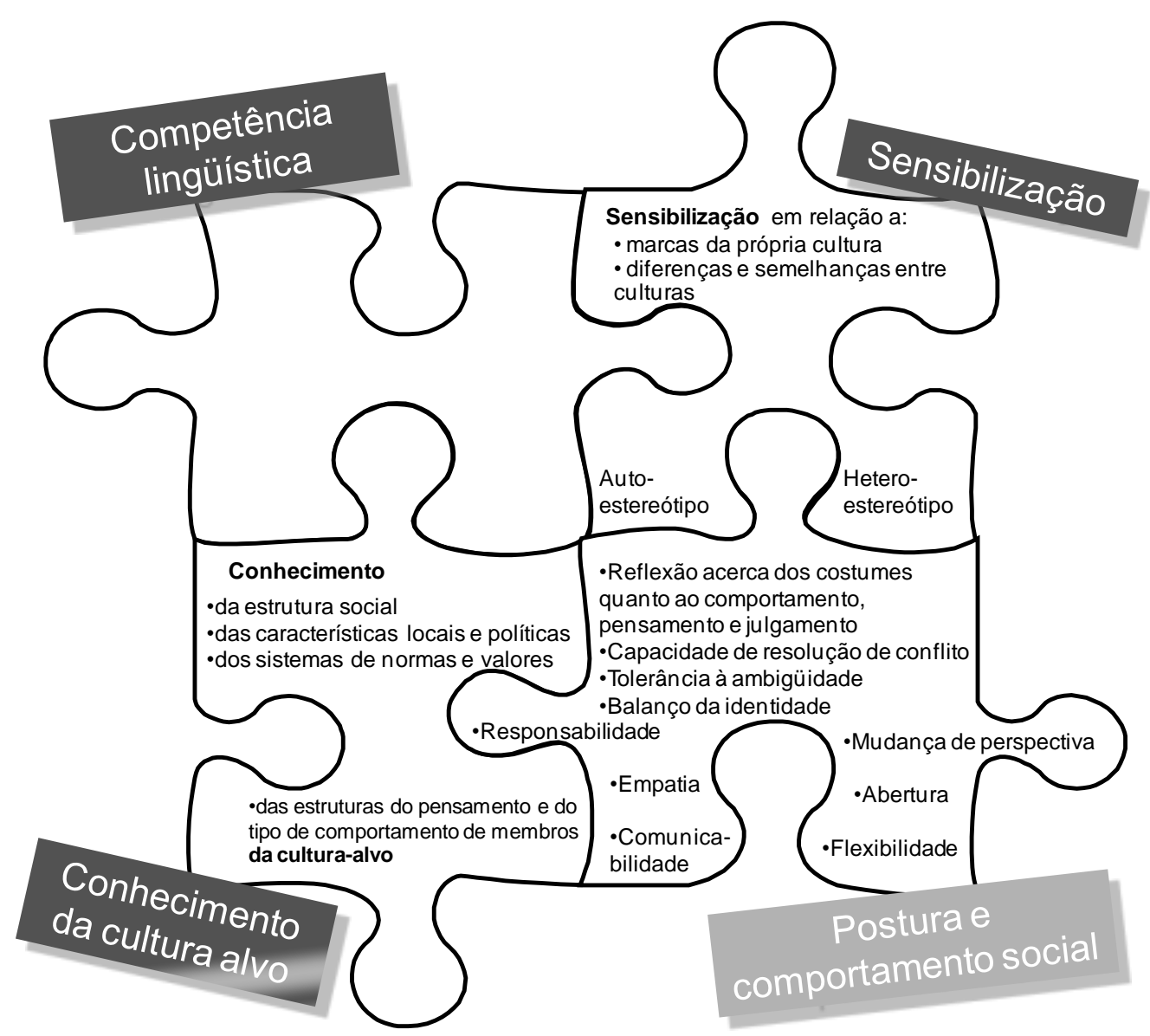

Figura 2: Representação dos diferentes elementos envolvidos na CI

Conforme a autora, o autoestereótipo (Autostereotyp) se refere às hipóteses explicativas de um determinado grupo social para sua autocaracterização (por exemplo, uma nação se explica por meio de sua existência histórica e social). O heteroestereótipo (Hetereostereotyp) representaria as caracterizações utilizadas para os outros grupos sociais.

BYRAM (2000: s/p) afirma que "uma pessoa com algum grau de CI é aquela capaz de ver relações entre diferentes culturas - tanto internas quanto externas - e de mediar, ou seja, interpretar cada uma a partir da perspectiva do outro, para os outros ou para si mesma" ${ }^{13}$. Além disso, essa pessoa se caracteriza por apresentar facilidade para

13 “.... someone with some degree of intercultural competence is someone who is able to see relationships between different cultures - both internal and external to a society - and is able to mediate, that is interpret each in terms of the other, either for themselves or for other people. It is also someone who has a critical or analytical understanding of (parts of) their own and other cultures - someone who is conscious of their own perspective, of the way in which their thinking is culturally determined, rather than believing that their understanding and perspective is natural." 


\section{Rozenfeld, C.Niana, N. - O desestranhamento}

ter uma compreensão crítica e analítica da própria cultura e de outras, bem como consciência de que sua perspectiva pessoal, sua forma de pensar, não são naturais, mas determinadas culturalmente.

BRUN (2004) afirma que o processo de aprendizagem de uma língua é complexo, na medida em que o sujeito se apropria de novos saberes, valores e sentimentos ao adquirir conhecimentos desse idioma e desenvolver competências interculturais. Dessa forma, a autora considera importante definir estratégias didáticas que favoreçam reflexão e revisão pessoal sobre valores do mundo e que possibilitem e intensifiquem as trocas culturais.

O conceito competência intercultural encontra seus opositores na justificativa de tratar-se de termo abrangente, já abarcado pela noção, por exemplo, de competência social, cultural, pragmática, a transcultural, além da competência comunicativa (cf. HAUSSTEIN 2005). Todavia, defendemos a CI como aquela que prioriza e possibilita o desenvolvimento da tolerância, da capacidade de aceitação das diferenças, a melhor compreensão do outro e do próprio, bem como possíveis reformulações de (pré) conceitos.

No Brasil, encontramos importantes estudos com foco no ensino de LE com base intercultural.

MотA et al. (2004) reuniram trabalhos do campo da interculturalidade que abordam questões relativas à promoção de consciência cultural crítica em relação à construção de uma identidade fortalecida, ao desenvolvimento de uma competência multicultural e à formação intercultural humanizadora de professores de LEs. Elas se opõem à rigidez pré-fixada dos roteiros didáticos de sala de aula, ao silenciamento da voz do aluno, à imposição de padrões interculturais estereotipados e à ausência de uma política pedagógica que promova a construção de um espírito de cidadania mais humana. Dessa forma, as autoras buscam situar a língua em um contexto sócio-cultural historicamente constituído, considerar os componentes identitários de alunos e integrar os conteúdos linguísticos em cenários pluriculturais, mediadores de uma conscientização intercultural crítica, a partir do reconhecimento da cultura de origem (MotA et al. 2004: 13) 


\section{Rozenfeld, C.Niana, N. - O desestranhamento}

A própria cultura dificilmente é vista de forma crítica, conforme afirma ZINK BolOGNINI (1993). A autora aponta dois principais objetivos do ensino intercultural: promover tal visão crítica da própria cultura e possibilitar o contato com outra.

Em trabalho que se caracterizou como inovador no campo do ensino e aprendizagem de língua alemã, PIRES E ROHRMANN (1990:5) descreveram as diretrizes de um livro didático para ensino de alemão no Brasil com o objetivo do desenvolvimento de "comunicação intercultural", ou seja, de levar o aluno a desenvolver a capacidade de "interpretar outras formas de comportamento, concepções e valores de uma cultura diferente, tendo como pano de fundo sua própria cultura e suas experiências pessoais". Segundo os autores, a experiência de vida dos alunos brasileiros deve ser o ponto de partida do processo de aprendizagem. O livro didático proposto pelos autores tem como principal objetivo levar os alunos à aquisição dos conhecimentos acerca de uma cultura, até então estranha, pelo filtro do já conhecido.

Concluímos este item enfatizando a relevância de compreender os conceitos de língua e cultura como amplos e indissociáveis e de estranho em relação dicotômica ao de próprio. Posicionamo-nos ainda em consonância com estudos que apontam para a necessidade de um ensino de alemão por uma perspectiva intercultural, visando a compreensão e reelaboração das imagens de alunos quanto à língua e cultura-alvo.

Abordaremos no próximo item, sob a perspectiva de desestranhamento e do desenvolvimento de competência intercultural, os dados de uma pesquisa cujo enfoque recaiu principalmente sobre imagens quanto à língua e povo, apresentadas por candidatos a um curso de alemão, bem como por aprendizes que efetivamente o realizaram.

\section{A pesquisa: contextualização, instrumentos, participantes e metodologia}

Com base nas discussões teóricas apresentadas e nas distintas experiências advindas da atuação dos autores deste trabalho, de um lado como professora e pesquisadora da área de ensino de alemão e, de outro, como professor e pesquisador da área de ensino e 


\section{Rozenfeld, C.Niana, N. - O desestranhamento}

aprendizagem de línguas estrangeiras, intrigou-nos o fato de que existem muitas associações negativas relacionadas ao idioma e ao povo alemão ${ }^{14}$. Diante disso, a mola propulsora para o desenvolvimento da pesquisa que apresentaremos foi o fato de que, dentre as pessoas que apresentam imagens com caráter negativo e estereotipado, existem aquelas que:

a) na busca pela aprendizagem de uma segunda língua estrangeira, reconhecem a importância do alemão no quadro político-econômico atual. Todavia, elas se desmotivam a aprendê-lo, em decorrência da imagem de que o idioma é "muito difícil", "incompreensível", "impossível", optando frequentemente pela aprendizagem de outra língua estrangeira "mais fácil" e renunciando, assim, à intenção de iniciar a aprendizagem do idioma alemão;

b) apesar de suas imagens estereotipadas de que o idioma alemão é "difícil”, ou o povo alemão "frio, agressivo", optam, ainda assim, pela aprendizagem da língua, vislumbrando um diferencial no mercado de trabalho;

c) ao iniciarem a aprendizagem de alemão como LE, adentram a sala de aula imbuídas de imagens estereotipadas sobre a língua e o povo, antes mesmo de terem tido qualquer contato direto com o idioma e a cultura. Tais imagens são constituídas, possivelmente, no contexto sócio-cultural em que esses alunos se encontram;

d) associam imagens negativas da língua ao povo (por exemplo: "os alemães parecem estar sempre brigando, são agressivos)”.

Com relação à recorrente associação do alemão com língua difícil, não nos deparamos com estudos que possam legitimar essa caracterização, fato que nos levou a considerar tratar-se de um estereótipo. Em nossa percepção, cada língua possui suas peculiaridades

\footnotetext{
14 cf. ROZENFELD (2007), dissertação que analisa as imagens sobre a língua e a cultura alemã: "Crenças sobre uma língua e cultura-alvo (alemã) em dimensão intercultural de ensino de língua estrangeira" 


\section{Rozenfeld, C.Niana, N. - O desestranhamento}

e dificuldades específicas, não existindo língua fácil ou difícil. Todavia, determinadas línguas são fortemente categorizadas dessa forma no imaginário de algumas pessoas.

Observamos, ainda, na prática de ensino de alguns professores de alemão, que eles não revelam, em sua atuação pedagógica, conhecimento ou consciência acerca das implicações das imagens de seus alunos sobre a língua e o povo no processo de aprendizagem. Por carecerem de tal conhecimento, adotam, por vezes, procedimentos em sala de aula que podem intensificar imagens negativas, fato que acreditamos poder refletir na aprendizagem reduzindo a motivação para o aprendizado da língua.

Tomando tais premissas como ponto de partida, ROZENFELD (2007) desenvolveu uma pesquisa com o intuito de analisar imagens sobre o idioma e o povo alemão, apresentadas por estudantes universitários, primeiramente na condição de interessados na aprendizagem desse idioma e posteriormente na condição de aprendizes do mesmo, em um curso para iniciantes. A autora atribuiu a essas imagens, uma caracterização abarcada pelo conceito de crenças $^{15}$.

Para a constituição do corpus da pesquisa, foi oferecido, para a comunidade acadêmica de uma universidade pública situada no interior paulista, um curso de extensão “Alemão para iniciantes”, cujo grupo deveria ser constituído por 20 alunos.

Como procedimento de inscrição ao curso, foi requerido dos interessados o preenchimento de uma ficha no formato de questionário ${ }^{16}$ com questões abertas, que era acessado pela internet e que deveria ser enviado a um endereço eletrônico criado para recepção dos formulários.

Além de dados e informações pessoais (nome, idade, sexo, indicação do curso de graduação que frequentava, ano de ingresso, telefone e email para contato, idade), o formulário continha questões abordando:

1. informações acerca do conhecimento de alemão e de outras línguas estrangeiras (francês, espanhol, inglês, outras), com a solicitação de

\footnotetext{
15 cf. conceito e caracterização das crenças cunhados por ROZENFELD (2007) e ROZENFELD E VIANA (2008).

${ }^{16} \mathrm{Na}$ divulgação do curso, foi informado que a atividade estava relacionada ao desenvolvimento de pesquisa de mestrado e solicitou-se no questionário (ficha de inscrição) a autorização do candidato para utilização dos dados.
} 
indicação do nível de proficiência e do local onde eventualmente havia estudado/aprendido;

2. imagens sobre a língua alemã: questões sobre razões para se estudá-la, sobre impressões/percepções ao escutá-la, imagens que se faz dela e indicações de possíveis razões para isso e sobre contato prévio com o idioma;

3. imagens sobre o povo relacionado ao idioma alemão: questões sobre a relação atual e prévia com falantes de língua alemã, imagens sobre o povo alemão e possíveis razões para elas;

4. a relação atual com a cultura alemã, por exemplo, com a literatura, a música, a arte, com estudos científicos, lugares, pessoas, etc.

Foram recebidas 233 inscrições, cujos questionários constituíram o corpus da primeira fase da pesquisa, em que foram analisados os dados de todos os candidatos. Na segunda fase, conforme descreveremos, foram coletados e analisados os dados dos 20 alunos selecionados para o curso.

Tendo como base as respostas contidas nos questionários (inscrições), foi possível traçar um perfil dos candidatos ao curso e uma caracterização das imagens preponderantes que eles apresentavam em relação à língua e à cultura alemãs e ao povo.

Para participação no curso, priorizou-se a seleção de alunos que revelavam imagens notadamente estereotipadas sobre a língua alemã (difícil, agressiva, impossível, etc.) e sobre o povo (frios, distantes), e que correspondiam aos critérios para seleção estabelecidos e divulgados previamente, a saber: ser brasileiro, estudante de graduação ou pós-graduação e não ter conhecimento prévio da língua.

Para constituição do corpus na segunda fase da investigação, ou seja, durante o curso, além de tomarmos como base o questionário enviado para inscrição, consideramos ainda as respostas obtidas em questionário aplicado ao final do curso, bem como os dados coletados por meio de duas entrevistas ${ }^{17}$ (transcritas) realizadas

\footnotetext{
${ }^{17}$ Inicialmente concebido e caracterizado como entrevista, o procedimento de coleta desses registros ocorreu de maneira mais próxima à técnica de grupo focal que, de forma geral, pode ser entendida, segundo IERVOLINO E PELICIONI (2001), como o desenvolvimento de interação propositada 


\section{Rozenfeld, C.Niana, N. - O desestranhamento}

com o grupo de aprendizes em sala de aula, e as anotações (registros) de uma auxiliar de pesquisa (uma candidata ao curso, aluna de pós-graduação em Linguística, que foi convidada a participar como aluna-observadora).

No que concerne ao papel dessa aluna (auxiliar de pesquisa), destacamos que lhe foi esclarecido quais eram os objetivos de sua atuação, a saber, observar e anotar atitudes e reações dos demais aprendizes, durante as aulas, ou em conversas extraclasse, que pudessem fornecer dados sobre o processo de aprendizagem e as crenças dos mesmos.

Considerando os procedimentos de coleta de dados e a perspectiva interpretativista adotada para análise, apontamos a inserção da pesquisa no paradigma qualitativo, ressaltando sua característica de estudo exploratório e sua natureza etnográfica, cuja compreensão, aceita na área educacional por vários autores, pode ser resumida pelo que aponta MOITA LOPES (1995:23), para quem a pesquisa etnográfica é caracterizada por colocar o foco na percepção que os participantes têm da interação linguística e do contexto social em que estão envolvidos.

Para compreensão mais ampla do contexto de realização do estudo, consideramos pertinente acrescentar informações referentes ao curso oferecido, ressaltando, inicialmente, que ele teve como principais objetivos:

1. criar ambiente para coleta de dados;

2. proporcionar conhecimento básico da língua alemã a estudantes de graduação e de pós-graduação: buscar capacitar os alunos nas quatro habilidades exigidas no nível $\mathrm{A} 1$, do quadro comum de referência europeu $^{18}$.

3. estudar a configuração das crenças dos alunos em relação à língua e à cultura alemã, antes, durante e ao final do curso.

(discussão) entre o pesquisador e os demais participantes, visando obtenção de dados a partir de tópicos direcionadores, relacionados ao estudo.

${ }^{18}$ Segundo o quadro comum de referência europeu, o aluno deve, no nível A1, ter "a capacidade de compreender e utilizar frases e expressões cotidianas simples; capacidade de apresentar-se, elaborar perguntas simples sobre outras pessoas e responder a perguntas desta natureza; capacidade de comunicarse de maneira simples, quando o (a) interlocutor(a) fala lenta e claramente." (http://www.goethe.de/ins/br/sap/lrn/stf/ptindex.htm). 
O livro didático utilizado foi o Tangram Aktuell 1 - Lektionen 1- 4. Durante o curso, buscamos adotar procedimentos metodológicos que pudessem contribuir para aumento da motivação, do interesse e do prazer na aprendizagem, e para um baixo grau de ansiedade, bem como para promover uma aproximação de culturas. Tais propostas foram calcadas em pressupostos teóricos do ensino intercultural, sob os quais se defende, entre outros aspectos, a importância no processo de ensino de LE de se criarem situações relevantes de comunicação para os alunos, de se promover a discussão acerca das diferentes culturas e o desenvolvimento de atividades que possam contribuir para melhor compreensão do outro e maior conhecimento do próprio, considerando-se os aspectos afetivos e a formação geral do aluno.

Procuramos diversificar as atividades propostas ao longo do curso, utilizando recursos como jogos, músicas, filmes, figuras, simulações de situações do dia-a-dia, a partir de conteúdo do livro didático ou de material extra. Buscou-se constantemente criar situações "autênticas" de comunicação e interação ${ }^{19}$, bem como aproveitar as que surgissem imprevisível e naturalmente em sala de aula e que fossem relevantes aos alunos, a fim de estimular e motivar o uso verossímil da língua-alvo.

Tendo ainda como respaldo os pressupostos do ensino intercultural, procuramos levar os alunos à reflexão crítica sobre a própria cultura e possibilitar o contato com aspectos da cultura-alvo, por meio de discussões sobre temas distintos relacionados às duas culturas envolvidas. Incentivamos ainda a constante busca pelo contato com a cultura alemã fora de sala de aula, por meio de músicas, filmes, programas de TV e de outros recursos possibilitados pela internet.

Dentre as atividades realizadas, destacamos: a) apresentação de e discussão sobre situações do dia-a-dia como, por exemplo, as formas mais usuais de se apresentar, se cumprimentar, de atender ao telefone, de aceitar e recusar convites; b) discussão sobre padrões de comportamento no Brasil e na Alemanha, com base em diálogos realizados (por exemplo, na situação de um encontro com amigos em restaurante, o uso de "Prost", "Guten Appetit", etc), e sobre possíveis razões para as diferenças existentes,

\footnotetext{
${ }^{19}$ Entendemos que a noção de "situação autêntica" é relativa e poderia ser discutida mais profundamente, na medida em que o contexto é o de situações hipotéticas de sala de aula, No entanto, utilizamos o termo para nos referir a situações comunicativas utilizadas em sala de aula.
} 


\section{Rozenfeld, C.Niana, N. - O desestranhamento}

c) indicação de sites e de filmes alemães disponíveis em locadoras, d) apresentação, didatização e discussão de músicas e trechos de filmes etc.

Os filmes selecionados para didatização foram: "Good bye Lenin" e "Die fetten Jahre sind vorbei”.

A escolha do filme Good bye Lenin se deu com o objetivo de promover confronto e debate de aspectos da história alemã nele abordados. Além de fonte de insumo significativo, o filme apresenta, em tom que também explora o humor, o contexto da reunificação da Alemanha. Com base em um roteiro de atividades préelaborado, foram discutidos (na LM) aspectos desse importante contexto histórico. A escolha do segundo filme, por outro lado, ocorreu por razões linguísticas específicas.

No decorrer do curso, foram coletados dados dos participantes (aprendizes) sobre imagens (crenças) acerca do idioma e do povo alemão, em dois momentos, sendo o primeiro após algumas semanas de aula e o segundo, ao final do curso.

A partir de similaridades encontradas entre as imagens dos alunos do curso e dos candidatos a ele, propusemos uma categorização das crenças, agrupando-as sob as denominações: tipicalizadas, comparativas e relativizadas.

As crenças tipicalizadas são compreendidas/definidas como aquelas marcadas por estereótipos, originados na memória coletiva e no contexto social; as comparativas são aquelas decorrentes da comparação com outra língua estrangeira, e as relativizadas são as resultantes de maior reflexão e fundamentação, sendo por vezes embasadas por vivência na cultura-alvo, com membros dela ou com pessoas próximas que trouxeram maior fundamentação para a sua constituição.

Dos dados obtidos na primeira fase, as crenças tipicalizadas, verificadas em respostas encontradas nos questionários dos 233 candidatos (incluindo, portanto, aqueles dos estudantes selecionados para o curso), são: 
Rozenfeld, C.Niana, N. - O desestranhamento

Tabela 1: Crenças Tipicalizadas quanto à língua alemã

\begin{tabular}{|c|c|c|}
\hline $\begin{array}{c}\text { CRENÇAS } \\
\text { TIPICALIZADAS }\end{array}$ & TOTAL & Descrição \\
\hline Difícil & 76 & $\begin{array}{c}\text { Difícil pronúncia; de difícil compreensão; complicada; difícil } \\
\text { de falar, de pronunciar, extremamente ou bem difícil, um pouco } \\
\text { difícil }\end{array}$ \\
\hline Fonética forte & 45 & $\begin{array}{l}\text { Sons guturais, sons difíceis; entonação forte; pronúncia difícil, } \\
\text { rápida; difícil pelo " } r \text { ", ríspida e seca, são as principais marcas }\end{array}$ \\
\hline Agressiva & 15 & $\begin{array}{c}\text { Língua rude; áspera; dura; imponente; autoritária; } \\
\text { imperativa; remete aos bárbaros; impositiva; pessoas parecem } \\
\text { estar brigando }\end{array}$ \\
\hline Palavras grandes & 11 & Língua é caracterizada por suas palavras grandes \\
\hline Estranha & 7 & Caracterização da língua como estranha \\
\hline $\begin{array}{l}\text { Difícil/muitas } \\
\text { consoantes }\end{array}$ & 4 & $\begin{array}{l}\text { Dificuldade da língua está no fato de apresentar palavras com } \\
\text { muitas consoantes }\end{array}$ \\
\hline Uma das mais difíceis & 2 & A língua é caracterizada como uma das mais difíceis \\
\hline Grafia estranha & 2 & Apresenta grafia caracterizada como estranha \\
\hline Feia & 1 & A língua é caracterizada como feia \\
\hline Lembra Hitler & 1 & Relação da língua com a figura de Hitler \\
\hline Total (menções) & 164 & $70 \%$ \\
\hline
\end{tabular}

Nota-se que imagens sobre a língua alemã, com caráter estereotipado, correspondem a $70 \%$ do número total de crenças encontradas, percentual bastante significativo e que pôde confirmar a hipótese inicial da pesquisa. A grande recorrência da percepção da língua como difícil decorre, prioritariamente, de acordo com os apontamentos, das particularidades de sua pronúncia. Sobre o povo alemão, foram registradas as imagens de caráter estereotipado expostas na Tabela 2. 
Rozenfeld, C.Niana, N. - O desestranhamento

Tabela 2: Crenças Tipicalizadas quanto ao povo

\begin{tabular}{|c|c|c|}
\hline $\begin{array}{c}\text { CRENÇAS } \\
\text { TIPICALIZADAS }\end{array}$ & Total & Descrição \\
\hline Frios & 19 & estranhos,racionais \\
\hline Fechados & 17 & reservados, sérios, individualistas \\
\hline Disciplinados & 15 & $\begin{array}{l}\text { sistemáticos, regrados, organizados, pontuais, } \\
\text { rigorosos }\end{array}$ \\
\hline Sérios & 11 & Rígidos \\
\hline $\begin{array}{l}\text { Preconceituosos e/ou } \\
\text { autoritários }\end{array}$ & 8 & $\begin{array}{l}\text { Racistas, dominantes; autoritários; xenófobos; } \\
\text { nacionalistas }\end{array}$ \\
\hline Conservadores & 7 & nacionalistas, preservam sua cultura \\
\hline Nazismo & 6 & $\begin{array}{l}\text { Associação ao nazismo, a Hitler, abordam o nazismo } \\
\text { como referência aos alemães }\end{array}$ \\
\hline Diretos/objetivos & 2 & \\
\hline Agressivos & 1 & rudes, guerreiros \\
\hline Organizados & 1 & \\
\hline Arrogantes & 1 & \\
\hline TOTAL & 88 & \\
\hline
\end{tabular}

Com base nos dados da tabela 2, podemos observar que as crenças mais recorrentes sobre o povo alemão são sinalizadas por meio dos descritores "frio", "distante", seguidos de "fechado", "disciplinado" e "sério". Notamos que foram poucos os estudantes que associaram os alemães ao nazismo. Apesar de ainda existir tal associação, ela não se configura como amostra representativa. Todavia, existe um número um pouco maior de estudantes que percebe o povo alemão como "preconceituoso".

Observamos, ainda, que as imagens sobre o povo demonstraram ter um caráter menos estereotipado do que aquelas sobre a língua. Além disso, nem todas as imagens estereotipadas se configuram como negativas, pois temos, por exemplo, as que caracterizam o povo como "organizado" ou "objetivo".

Entretanto, verifica-se a prevalência de imagens estereotipadas, de caráter negativo, tanto em relação à língua, quanto em relação ao povo, o que, seguramente, pode resultar em dificuldade, bloqueio ou atitudes de resistência no/para o processo de aprendizagem. 
Reafirmamos, portanto, nossa defesa em relação à necessidade de uma perspectiva intercultural no ensino de alemão como LE, visando contribuir para proporcionar ou desenvolver o desvelamento de crenças, no sentido de sensibilização dos aprendizes em relação a elas, o que acreditamos, com base nos dados obtidos, ter sido possível no curso que serviu de base para a pesquisa.

\section{5. $\bigcirc$ desestranhamento do alemão $e$ indícios de desenvolvimento de competência intercultural}

Com base na análise dos dados dos 20 participantes da segunda fase da pesquisa, obtidos ao início, durante e ao final do curso, pudemos verificar que suas crenças sobre a língua, com características inicialmente tipicalizadas e negativas, passaram por um processo de relativização durante o desenvolvimento das aulas (ROZENFELD, 2008: 178). Tal fato foi mais fortemente observado ao final do curso, conforme podemos verificar em trechos extraídos dos questionários respondidos pelos aprendizes. Em resposta à pergunta sobre a percepção de alteração na visão da língua, encontramos, por exemplo, as seguintes declarações:

Nr. 14: (a língua) se tornou muito mais clara e mais lógica [...] não tenho mais medo de dar uma olhada num texto em alemão [...] não ouço mais a língua com bloqueios

Nr. 4: Minha visão deu uma guinada de 360 graus $^{20}$, afinal, descobri que o alemão é uma língua interessante estruturalmente (quanto à formação de palavras), não tão complexa como eu esperava, nem tão difícil quanto as pessoas dizem. [...] Hoje a língua já não me assusta mais.

Nr: 11: Não entendia o mecanismo de formação de palavras e pude ver que é simples e funcional, uma vez que é generalizável para as mais diversas palavras. A língua não aparenta ser tão difícil, porém continuo achando a pronúncia um desafio

Nr2: (minha visão sobre a língua...) Mudou bastante. Já não acho que seja uma língua tão complicada de se aprender ou mesmo estranha.

Nr.3 [...] minha visão foi alterada. Considerava o alemão uma língua super complexa. Hoje ainda considero super complexa, porém, por ter aprendido a lógica da formulação das palavras, passei a ter menos medo do idioma.

\footnotetext{
${ }^{20}$ Inferimos pelo teor da resposta da aluna, que ela quis se referir, metaforicamente, a uma oposição total em relação à visão anterior, que corresponderia, portanto, a uma alteração de 180 graus, e não 360
} 
Nr.9: Muito. Achava que seria muito, muito, muito difícil aprender. Algumas vezes em que pensei em estudar alemão, cheguei a duvidar que seria capaz para isso.

Nr.10:Foi sim (a visão foi alterada sim). [...] a língua se tornou mais familiar, ela não parece mais tão 'áspera', tão difícil de ser compreendida.

Nr.13:Após a apresentação da língua alemã que tive com este curso, descobri que esta linguagem não é difícil, mas sim, uma língua com formação de palavras e frases diferentes da nossa

Nr.17: Anteriormente achava somente complicada. Hoje considero uma língua, além de muito interessante, bem objetiva e detalhada. Não considero tão complicada mais, porém é bem trabalhosa.

Foi possível observar também, nos dados da entrevista final com o grupo, uma mudança significativa das crenças, que passaram de tipicalizadas para relativizadas para a maioria dos alunos. Ao serem indagados, se a visão que tinham do alemão mudou após o curso, a resposta foi quase uníssona: "mudou muito". Dela seguiram-se comentários individuais, como, por exemplo:

Ma: porque antes eu achava que alemão..era uma língua agressiva..e..no decorrer do curso eu descobri que é só uma língua estrangeira, como qualquer outra e..não tem mais..a sensação de me assustar assim, uma pessoa falando alemão..sabe,num ta como preconceituosamente a gente acredita que esteja xingando a gente

R: [...] toda aquela parte característica de agressividade da língua se perdeu. Não parece mais ser tão grave quanto era antes. Parece que suavizou. ((inint)) habituado, mesmo.

Cr: Não sei, pra mim foi muito difícil aprender a falar.. pelos sons, mas..depois que a gente aprende, assim, a formação das palavras, até os números, né, que são enormes, aí a gente vê que não é difícil, que é até mais fácil, é lógico, né..eu acho que foi isso

D: eu acho que ((inint)) aquelas palavras enormes, que nem economista lá..

((risos))

D: ..é bem clara, né, é grande só que.. o significado é muito pontual, assim, você só juntou duas coisas que você quer dizer, então ela é bem..objetiva

Professor: e isso então mudou na sua visão..

D: é eu achava ela era complicada, né mas..é também um pouco ainda, só que é mais..é mais objetiva do que a nossa..nessa questão da formação é mais..mais direta

E: [...] pra mim..uma visão que eu tinha antes, de que o alemão era mais difícil do que o inglês, pra quem nunca ouviu a língua..pro falante latino, eu acho que ficou mais fácil, do que o inglês, do que o francês inclusive..pra um falante latino, porque são bem poucas diferenças, né, em termos de fonética. [...] a palavra Name, né.. Name ,é.. Frau..essas palavras,...du, né..você vê mais ou menos igual está no português, agora no inglês, $o \underline{\text { a }}$ pode teria o som de $\_$, né, o_p teria outro som..né..é...então..seria um pouco diferente.

Professor: a definição então da pronúncia é mais clara

E: exato 
Nota-se que a alteração das crenças quanto à língua, ocorreu, preponderantemente, com a relativização da imagem do alemão como língua complexa, presente no início do curso. Alguns afirmam ter percebido que ela não é tão difícil quanto acreditavam, ou que é uma língua lógica, clara, apenas diferente, mas não difícil. Outros ainda a consideram difícil, porém não mais impossível, inatingível, como antes.

Alguns passam a refletir sobre a presença de imagens estereotipadas com relação à língua:

E: antes eu estava..quando falava.. "o que você acha da língua e da cultura alemã" eu falava "ah , eu acho complexo. Muito difícil." E esse complexo era carregado de negatividade, porque não tinha..de mitos, né..porque não tinha exemplo nenhum, hoje eu acho complexo, mas não no sentido negativo, mas positivo, por exemplo:é..sempre achei que a língua alemã e a cultura alemã, eles eram ligados a..aquelas questões abstratas, de ficar realmente..quanto mais complexo um pensamento, uma idéia ou..ou uma área do conhecimento, melhor se adequa ao modo de ser do alemão, mas por outro lado tem coisas..e isso é até um mito mesmo, porque ..quando a gente viu aquele exemplo das siglas, né..que eles usam siglas pra um monte de coisas, ele falou até da praticidade, tudo, né.. poxa num..num é uma tendência abstrata não..eu acho que é pra tornar as coisas..mais práticas, determinadas coisas mais práticas, e isso é uma..questão..de todas culturas, tem coisa que você abstrai mais, tem coisa que você torna mais.. prático, [...] por isso..perdeu aquela idéia negativa..a questão da complexidade alemã, como eu disse..

Verificamos no excerto de $\mathbf{E}$, que ocorreu um processo de reinterpretação da língua como outra. A língua não deixou de ser complexa para muitos, mas deixou de ser estranha. $O$ conceito de complexo foi reinterpretado, reduzindo-se a carga negativa.

Entendemos tal reinterpretação da língua como parte do processo de aquisição de competência intercultural no sentido, por exemplo, de VOLKMANN (2002), WEIER (2002), STIERHOFER (2002), ByRAm (2002). A língua alemã, antes percebida como estranha, passa a ser mais percebida como outra, havendo revisão de estereótipos e maior sensibilização e aceitação do outro.

No sentido de Almeida FiLHo (1993: 7), podemos concluir que se iniciou um processo de desestrangeirização da língua. Entretanto, em nosso entendimento, o processo aponta não para a desestrangeirização da LE, mas para um desestranhamento dela, visto que a língua permanece(rá) estrangeira, porém, não mais “estranha".

De forma geral, os alunos apontaram também para um movimento de ampliação na curiosidade e no interesse pela língua: 
Cr: ((inint)) mesmo aqui na aula..eu lendo.. o enunciado do exercício, que geralmente eu não tenho todo o vocabulário, mas eu tento entender aquilo ali, eu tenho mais interesse em entender, porque eu não acho que é impossível, do jeito que eu pensava..

D: você fica mais próximo assim, igual todo mundo falou, né, você não tem mais aquela repulsa assim, pela língua alemã, você ouvia alguém falando, ouvia alguma coisa, você nem olhava..

M: acho que, como todos, cresceu o interesse, tanto pela língua quanto pela cultura, né..de você buscar..textos, tentar entender, esse negócio da palavra lá, descobrir o que aquilo quer dizer ((inint)) acho que isso modificou bastante, a questão do interesse mesmo em querer conhecer tanto a língua quanto a cultura e..até..é..o interesse assim..de querer aprender, de você ter curiosidade, né, aí eu, ás vezes eu fico em casa treinando sabe, falando em voz alta com..com as meninas lá de casa, ou com minha namorada, elas não entendem nada

Aliado a esses dados, verificamos também em registro feito pela aluna-observadora, evidências de alterações e ressignificação das crenças que cederam lugar até mesmo à descrição de prazer pelo estudo da língua:

Décima aula (30/04): Conversei com um colega de sala. Durante a conversa ele disseme que, antes do curso já pensava em fazer alemão por necessidade de trabalho. No entanto, quando ele se imaginava aprendendo a língua, 'torcia o nariz' e já achava difícil antes mesmo de conhecer, só de pensar já sentia dificuldade. Para ele, hoje, as aulas de alemão, são as únicas que dão prazer em estudar. A concepção do aluno já mudou bastante segundo ele.

Vigésima aula (04/06): ...A turma chegou a interagir para propor a continuação do curso no próximo semestre e também para indicar sites interessantes para ler e aprender um pouco mais sobre o alemão. Tais acontecimentos denotam motivação para aprender alemão. Penso que se há motivação é porque muitas idéias já foram (des)construídas. A pronúncia, os sons, a formação das palavras, antes percebidos como o grande "monstro" do idioma alemão, também se transformam em algo menos assustador:

Com relação às crenças sobre o povo alemão, os dados obtidos ao início da segunda fase, ou seja, no início do curso, revelam que ainda prevalecem algumas das crenças tipicalizadas, por exemplo, as de tratar-se de um povo sério, rígido, distante, formal, disciplinado, metódico, arrogante, xenófobo, mas também algumas relativizadas como inteligente, determinado. Apresentamos, a seguir, alguns excertos que podemos considerar como evidências desse fato:

Nr.2: Creio ser um povo bem nacionalista [...]

Nr. 7: O povo alemão parece bastante sério. 


\section{Rozenfeld, C.Niana, N. - O desestranhamento}

Nr.9: [...] o que predomina é a questão da frieza, da dureza, severidade, disciplina e rigidez

Nr.10: Não tenho contato com eles, mas aparentam ser muito formais, frios, distantes uns dos outros.

Nr.3: O pouco que conheço deste povo me faz acreditar que são extremamente inteligentes, determinados e metódicos.

An: eu acho que os alemães, pelas informações que eu tenho, eu acho eles super inteligentes, determinados e metódicos também.e..isso é o que eu acho do povo, né, por causa dos exemplos históricos que a gente tem [...] mas eu sei que eles bebem bastante cerveja ((risos)) e.. tem um tal de chucrutes também [...]

E: eu sempre tive uma impressão do povo diferente da cultura. Uma impressão negativa, até hoje eu confesso que eu tenho uma impressão negativa

P: em que sentido negativa?

E: eu sempre achei um povo um pouco arrogante em relação a outras culturas e o pouco que eu sei da história alemã, eles nunca ficaram subjugados lá no país deles, fora em outras histórias, mas sempre uma impressão de que eles olham pra todas as outras culturas de cima pra baixo

J: [...]eu não sei, eu acho assim, eu tenho a impressão,que ele é um povo bem mais disciplinado,então essa disciplina, assim ..parece que a língua junto dá essa impressão também, da pessoa ser mais rígida no que faz [...]

Quando questionados acerca das razões para tais crenças, alguns alunos apontam para acontecimentos, sobretudo históricos, que os levaram à configuração de suas crenças. Por exemplo:

Lu: ((inint)) o que eu aprendi na aula de história, sabe, lá na escola.., então agora, quando a gente vai falar do povo alemão a gente resgata isso, entendeu, é meio inevitável, né não tem jeito. Eu pelo menos não tenho muito conhecimento..é mais o que está ali..fossilizado, né, então você acaba resgatando aquilo, né..é meio inevitável.

Nr.13: Minha opinião se baseia no que aprende-se na escola e no que tenho visto às vezes na TV. O povo alemão é marcado por ser uma população com forte xenofobia, inteligente, com pensamento voltado para a tecnologia, disciplinados.

Ao final da segunda fase, ou seja, ao final do curso, a partir da triangulação dos registros obtidos nos questionários, na entrevista e nas anotações da aluna-observadora, verificamos que grande parte dos alunos menciona ainda manter suas crenças. Eles acreditam que isso se deve ao contato ainda restrito com o povo alemão e/ou com elementos da cultura alemã. No entanto, foi possível observar significativa ampliação da curiosidade e do interesse pela cultura-alvo (Excertos dos questionários):

Nr.18: Quanto ao preconceito e xenofobia, não pude ver nada que pudesse mudar minha visão, gostaria de saber mais sobre a cultura dos alemães. 
Rozenfeld, C.Niana, N. - O desestranhamento

Nr.4: Meu conhecimento não aumentou sobre o povo alemão [...] Contudo algumas experiências que a professora contou em sala, garantiram que a minha curiosidade não fosse dissipada.

Nr.6: Continuo pensando que seja um povo que, assim como os outros, possui características específicas de cultura, etc. Porém, a aprendizagem da língua fez com que meu interesse em estudar essa cultura e conhecer mais sobre esse povo aumentasse.

Além disso, nota-se a reformulação de algumas generalizações e reflexão sobre crenças tipicalizadas mais comuns, por exemplo:

Nr. 12: O povo alemão é um povo tipicamente europeu, mais frio que os brasileiros, existe nos povos alemães uma fama de serem mais rígidos. Esta opinião, por se basear em vivência, não se alterou. Por outro lado, trata-se de um estereótipo e deve-se sempre desconfiar de estereótipos.

Nr.8: [...] acredito que o problema usualmente dado como presente em todo o país, como o xenofobismo, estão restritos a alguns focos de insurgência. Acredito que pelos filmes alemães que tenho visto, eles me parecem menos frios que anteriormente, ainda que a imagem de que eles sejam sérios permaneça.

Nr.17: Penso que ao invés de frios, conforme disse no questionário inicial, eles sejam mais objetivos e diretos. Isso reflete muito no padrão linguístico, gramatical e cotidiano dos alemães.

Nr.14: Continuo achando eles um pouco arrogantes, mas a aproximação com a cultura derrubou alguns mitos sobre o povo da Alemanha especialmente.

Nr.11: Perdi meu viés mais negativo sobre os falantes de alemão. Porém continuo achando-os organizados e práticos, características que considero de grande importância para todos os resultados bem sucedidos que eles alcançaram nas mais diversas áreas do saber [...]. Apesar de frios, eles possuem uma sensibilidade incrível [...]

Nr.9: Um pouco bem mais reservado, mais centrados em si mesmos, mas não no sentido negativo [...]

Nr.5: A resposta continua a mesma, acho que são pessoas fechadas [...] mas a minha simpatia e respeito pelos alemães aumentou, pelo conhecimento da língua e também pelo jeito que ela vem sendo apresentada (a professora costuma dar informações sobre os costumes e isso parece o bastante para tornar os alemães mais próximos).

Nr.3: [...] continuo a achá-los frios, objetivos e diretos. Não vejo, entretanto, essas características como negativas, encaro apenas como uma visão que tenho dessas pessoas

Nr.2: Sinceramente, não creio que esses poucos meses de aula tenham sido suficientes para criar ou modificar a minha visão pessoal a respeito desses povos. [...] No entanto, agora com uma visão já não tão crítica e até mais propensa a mudar. [...]

Nr.10: Continuo sem conhecer nenhum alemão, mas acredito que quando conhecer algum, não vou mais encará-lo com aquele preconceito, não vou mais 'preparada' para encontrar uma pessoa fria, rígida e seca.

Dados obtidos por meio de entrevista (grupo focal), também corroboram a ocorrência de alterações:

Excertos da entrevista final: 
R: [...] tirou muito o tabu assim da..da minha cabeça..que eu tinha em relação ao pessoal germânico

S: eu achei que, que eles são muito educados..eu achei que não era tanto assim, eu achei que eles eram bem arrogantes assim..((inint)) danke pra tudo, Vielen Dank, aqueles negócio..

((risos))

Ma: [...] caiu um pouco do meu preconceito de achar que eles eram..sabe..aquelas pessoas..sei lá..do mal..

Em relação à ampliação de interesse dos alunos em relação à cultural alemã, são verificados aspectos evidenciadores em registros da aluna-observadora:

Vigésima-quarta-aula (15/06): (sobre a apresentação de trechos dos filmes Good bye Lenin e Die fetten Jahre sind vorbei) [...] Observei bastante interesse nos alunos para saber um pouco mais sobre a cultura alemã.

Vigésima-sétima aula (22/06)

[...] Novamente a curiosidade com relação à cultura alemã foi aflorada. Muitas perguntas que foram feitas demonstraram interesse pelo idioma e pela cultura alemã.

Sobre as razões para as mudanças nas imagens sobre a língua e o povo, os procedimentos metodológicos adotados foram apontados pela maioria como tendo sido determinantes.

(Questão: “Sua visão da língua foi alterada após o curso? O que contribuiu para isso?”):

Nr. 2: Sim. [...] A didática e dinamicidade nas aulas contribuíram para isso

Nr.4: Sim. [...] a língua me fascinou. Acredito que a maior responsável foi a professora, que nos fez acreditar que o alemão não era tão difícil quanto parecia.

Nr.6: Sim. As aulas foram o motivo principal para que o meu interesse sobre essa língua aumentasse, uma vez que foram muito motivadoras.

Nr.11: Sim. Com as aulas e com as discussões realizadas em sala pude ampliar a minha percepção sobre a cultura e a língua alemã [...]

Nr.14: Sim e muito. [...]A metodologia da professora e aproximação com a língua contribuíram.

Postulamos que muitas das imagens de natureza negativa, como a de língua "difícil”, ou de povo "frio", devem-se, comumente, a uma má compreensão das diferenças existentes 
entre os povos e as culturas. Tal percepção foi apontada por ROZENFELD (2007), que afirma:

Propomos, a partir da fundamentação teórica de crenças, do estranho em relação dicotômica ao próprio e de competência intercultural, que as crenças tipicalizadas e comparativas quanto à língua e cultura-alvo se originam, muitas vezes, do fato de não haver ainda uma boa compreensão das particularidades da língua e cultura-alvo. Dessa forma, inferimos que as crenças tipicalizadas sobre a língua e cultura-alvo se encontram inseridas no início do processo de aquisição de CI. O desvelamento das crenças, no sentido de sua conscientização, é parte necessária desse processo: a partir dele, será possível (re)avaliar padrões culturais da outra e da própria cultura, reformular conceitos e refletir sobre a própria identidade cultural. (ROZENFELD 2007:178-179)

\section{Considerações finais}

Este trabalho teve como objetivo discutir a importância de um percurso de desestranhamento em relação ao idioma (e por abrangência, em relação a características do povo) alemão, no processo de ensino e aprendizagem, sob a perspectiva de teorias de ensino e da competência intercultural, bem como da noção de outro e de estranho em relação dicotômica à de próprio.

As reflexões nele apresentadas foram baseadas nos trabalhos de ROZENFELD (2007) e RozENFELD/ ViAnA (2008), que abordam resultados de análise de crenças acerca da língua alemã e da cultura-alvo, reveladas em uma pesquisa com estudantes de uma universidade pública, interessados em estudar alemão, e com estudantes/aprendizes de um curso de alemão para iniciantes.

Postulamos neste trabalho que, no ensino de alemão como língua estrangeira, seja considerada e abordada a possível existência de imagens prévias estereotipadas sobre a língua e a cultura-alvo, que podem ser nocivas ao processo de aprendizagem. Por essa razão, defendemos que o ensino intercultural seja privilegiado, tendo como pilares o desenvolvimento da competência intercultural, que envolve inicialmente, no caso desse idioma, a necessidade de um processo de desestranhamento do outro, de reflexão e conhecimento acerca do próprio, de entendimento e diálogo entre culturas e de aceitação de diferenças. Defendemos, ainda, que o desestranhamento em relação à língua e a membros da cultura alemã sejam considerados no estabelecimento de 
objetivos de ensino e de procedimentos metodológicos, como parte do desenvolvimento de competência intercultural.

O professor deve considerar o fato de que muitos de seus alunos iniciam a aprendizagem de alemão imbuídos de imagens de natureza estereotipada com relação à língua e ao povo. A existência de estereótipos entre os alunos já foi apontada em investigações científicas como prejudicial à aprendizagem de LE. Assim, é importante que o professor reflita sobre tal fato e o considere no âmbito do estabelecimento dos procedimentos metodológicos, buscando aqueles que possam levar os alunos à reflexão crítica sobre suas crenças, à sensibilização em relação a diferenças na forma de pensar dos membros da cultura-alvo, ao desestranhamento do outro e à desconstrução de bloqueios e estereótipos.

\section{Referências bibliográficas}

Almeida FilHo, José Carlos Paes. Dimensões comunicativas no ensino de línguas. Campinas: Pontes, 2008, $73 \mathrm{p}$.

BAUSINGER, Hermann. Das Bild der Fremde in der Alltagskultur. In: WIERLACHER, A. ALBRECHT, C. Fremdgänge: eine anthologische Fremdheitslehre für den Unterricht Deutsch als Fremdsprache. Bonn: Internationes, 1998, 94-96.

BRUN, Millena. (Re)construção identitária no contexto da aprendizagem de Línguas Estrangeiras. In: MOTA, K.; SCHEYRL. D. (Orgs.) Recortes interculturais na sala de aula de línguas estrangeiras. Salvador: EDUFBA, 2004, 73-104.

BYRAM, Michael. Assessing intercultural competence in language teaching. Sprogforum, Kobenhavn, v. 6, n. 18, 2000, $8-13$.

http://inet.dpb.dpu.dk/infodok/sprogforum/Espr18/byram.html (26/02/2011)

CANALE, Michael; SwAIN, Merril. Theoretical bases of communicative approaches to second language teaching and testing. Applied Linguistics. Oxford: Oxford University Press, v.1, n.1, 198o, .1-47

DoRnBusch, Claudia. O olhar estrangeiro. Pandaemonium Germanicum, n.2, 1998, 13-21.

HAUSSTEIN, Alexandra. Interkulturelle Kompetenz - Theoretische Analyse und Beschreibung eines Kompetenzfeldes. DaF-Brücke: Zeitschrift der Deutschlehrerinnen und Deutschlehrer Lateinamerikas. Mexico, n. 7, 2005, 9-14.

Hogrebe, Wolfram. Die Epistemische Bedeutung des Fremden. In: WIERLACHER, Alois. ALBRECHT, Corinna. Fremdgänge: eine anthologische Fremdheitslehre für den Unterricht Deutsch als Fremdsprache. Bonn: Internationes, 1998, 103-109.

HYMES, Dell. On communicative competence. In: PRIDE, J.B.; HOLMES, J. (Eds.) Sociolinguistics. Harmondsworth: Penguin, 1972, 269-293. 
IERvolino, S.A.; PELICIONI, M.C.F. A utilização do grupo focal como metodologia qualitativa na promoção da saúde. Ver. Esc Enf USP, v. 35, n.2, p.115-21, jun, 2001. Disponível em http://www.scielo.br/pdf/reeusp/v35n2/v35n2a03.pdf . Acesso em abril de 2011.

KRAMSCH, Claire. Context and culture in language teaching. Oxford: Oup, 1993, 304 p.

Krusche, Dietrich; Grossklaus, Götz; WIERlacher, Alois. (Hrsg.). Hermeneutik der Fremde. München: Iudicium, 1990, 282p.

MoITA LOPES, L. P. Oficina de Lingüística Aplicada: a natureza social e educacional dos processos de ensino/aprendizagem de línguas. Campinas: Mercado de Letras, 1996.

MotA, Katia. ScheYRL, Denise. (Orgs.) Recortes interculturais na sala de aula de línguas estrangeiras. Salvador: Edufba, 2004, 21-34.

PIRES, M.C.A; ROHRMANN, L. Sprachbrücke: Deutsch als Fremdsprache-manual do professor. São Paulo: EPU, 1990, 219 p.

RozenFELD, Cibele. C.F. Crenças sobre uma língua e cultura-alvo (alemã) em dimensão intercultural de ensino de língua estrangeira. Dissertação de Mestrado. UFSCAR, São Carlos, 2007.

RozenFELD, Cibele. C.F. e ViAnA, Nelson. Eu acho o alemão uma língua... e o povo ...: crenças de alunos sobre a língua e cultura-alvo. Projekt, n. 46, 2008, 50-53.

STIERTORFER, K. Literatur und Interkulturelle Kompetenz. In: VOLKMANN, L.; STIERTORFER, K.; GeHRING, W. (Hrsg.) Interkulturelle Kompetenz: Konzepte und Praxis des Unterrichts. Tübingen: Gunter Narr Verlag, 2002, 119- 141.

VIANA, Nelson. Sotaque Cultural: uma proposta para compreensão de traços culturais (re)velados na interação em Língua Estrangeira. 2003. 319f. Tese de Doutorado. UFMG, Belo Horizonte, 2003.

VolKMANN, Laurenz. Aspekte und Dimensionen interkultureller Kompetenz. In: VOLKMANn,L; STIERTORFER,K; GeHRING, W. (Hrsg.) Interkulturelle Kompetenz: Konzepte und Praxis des Unterrichts. Tübingen: Gunter Narr Verlag, 2002, 11-48.

VolLmUTH, Isabel. Möglichkeiten der Initiation interkulltureller Lernprozesse im Englischunterricht an der Grundschule. In: VOLKMANN, L.; STIERTORFER,K.; GEHRING, W. (Hrsg.) Interkulturelle Kompetenz: Konzepte und Praxis des Unterrichts. Tübingen, Gunter Narr Verlag, 2002, 49-68.

WEIER, Ursula. Interkulturelles Lernen und Stereotype englischer Alltagskultur. In: VOLKMANN, L.; STIERTORFER, K.; GeHRING, W. (Hrsg.) Interkulturelle Kompetenz: Konzepte und Praxis des Unterrichts. Tübingen, Gunter Narr Verlag, 2002, 165-191.

WEINRICH, Harald. Fremdsprachen als fremde Sprachen. In: WIERLACHER, Alois; ALBRECHT, Corinna. Fremdgänge: eine anthologische Fremdheitslehre für den Unterricht Deutsch als Fremdsprache. Bonn, Internationes, 1998, 15-19.

WIDDOwsOn, H.G. Teaching language as communication. Oxford: OUP, 1978, 168p.

WIERlACHER, Alois; ALBRECHT, Corinna. Fremdgänge: eine anthologische Fremdheitslehre für den Unterricht Deutsch als Fremdsprache. Bonn: Internationes, 1998, 9-10.

WIERLACHER, Alois; STÖTZEL, G. Blickwinkel. Kulturelle Optik und interkulturelle Gegenstandskonstitution. Akten des III. Internationalen Kongresses der Gesellschaft für Interkulturelle Germanistik, Düsseldorf , 1994.

ZINK BoLOGNINI, Carmen. Estereótipos e ensino intercultural. Projekt, n. 10, 1993, 21-25.

Recebido em 01/03/2011

Aprovado em 15/04/2011

Pandaemonium, São Paulo, n. 17, Julho/2011, p. 259-288 - www.fflch.usp.br/dlm/alemao/pandaemoniumgermanicum 